\title{
Project Selection of Government Guarantee in BOT/PPP Project Finance
}

\author{
Ping Li \\ Luoyang Institute of Science and Technology, Luoyang, China \\ Email:LiP05@163.com
}

How to cite this paper: Li, P. (2020). Project Selection of Government Guarantee in BOT/PPP Project Finance. American Journal of Industrial and Business Management, 10, 1107-1120. https://doi.org/10.4236/ajibm.2020.106073

Received: May 9, 2020

Accepted: June 7, 2020

Published: June 10, 2020

Copyright (c) 2020 by author(s) and Scientific Research Publishing Inc. This work is licensed under the Creative Commons Attribution International License (CC BY 4.0).

http://creativecommons.org/licenses/by/4.0/

(c) (i) Open Access

\begin{abstract}
Based on multi-objective programming method, this paper reviews the previous research on the problem of government guarantees in the project financing, and puts forward the importance of the research on project selection of government guarantee in Build-Operate-Transfer (BOT) or Public Private Partnership (PPP) project finance. Through the analysis of the selection criteria of guarantee project, we find that the selection problem of government guarantee of BOT/PPP infrastructure projects is essentially a multi-objective decision problem. Moreover, we establish a chance-constrained objective programming model for the government to make the decision to guarantee project selection.
\end{abstract}

\section{Keywords}

BOT/PPP Project Finance, Government guarantee, Project Selection, Multi-Objective Chance-Constrained Programming Model

\section{Introduction}

Infrastructure, as the foundation of urban survival, is the guarantee of the national economy and the sustainable development of society. In order to satisfy the requirement of rapid economic development in China, the scale of infrastructure construction has been increasing continually. But the funds needed for large-scale construction and maintenance of infrastructure have far exceeded the government's financial capacity, and the government is facing a huge funding gap for infrastructure construction. In order to improve this unfavorable situation, project financing comes into being. Project financing develops rapidly with its strong advantages such as strong financing ability and flexible financing method, so it also attracts the attention of scholars. Project financing is a specific financing method with no recourse or limited recourse, which is based on the 
future income and assets of the project. The research and practice of project financing of infrastructure construction began in the U.K. and quickly extended to other western countries. With the continuous deepening of its theoretical research and the accumulation of practical experience, it has gradually formed various project financing models of private capital participating in infrastructure projects. Project financing was introduced into China in the 1990s, and then there was an upsurge of research on project financing. Based on the research and practice from western countries, Chinese scholars have studied the financing of infrastructure projects considering the specific situation in China. The main issues of the research include project financing model (Zhao \& Wang, 2010), investment and financing structure (Lin, Chen, \& Ma, 2005; Yu, Zhou, \& Wu, 2012), investment and financing institutional mechanism construction (Huang \& Liu, 2008), project financing risk management (Ye \& Zhou, 2010), and incentive and supervision of project financing (Zhang \& Guo, 2009). The risk of the project is shared by its participants (Dai, 2012). One of the biggest characteristics of project financing is that it can realize project risk diversification and risk isolation, and improve the possibility of success for a project and government guarantee is one of the main tools of project risk sharing. In terms of the projects, government guarantee can reduce political risk and economic policy risk, which enhances the investment confidence for investors and ensures the smooth implementation of the projects; in terms of the government, government guarantee can obtain more infrastructure construction financing with fewer funds and credit, which relieves the financial pressure. Therefore, government guarantee plays an important role in project financing.

Scholars have studied the problem of government guarantee from different perspectives, roughly in the following aspects. The first is the research on the influencing factors of government guarantee. Sun, Guo, Gao et al. (2007) suggested that the guarantee provided by the government is mainly reflected in the promise of franchise, investment return, investment environment and investment conditions. Gong, Guo, \& Gao (2011) showed that the level of government guarantee depends on the project attributes, and it also has a significant impact on the enthusiasm of investors. The second is the study of the concession period under government guarantee. Based on the assumption that project income obeys the geometric Brownian motion, Gong, Guo, \& Zhang (2008) use game theory and real option method to establish the quantitative decision model of concession period in the condition of government guarantee. The third is the study of the value of government guarantee. Gao, Zhang, \& Du et al. (2005) applied the real option theory to calculate the value of full guarantee and non-full guarantee in the guarantee of government economic policy, and obtain a guarantee value which is relatively close to the actual value. Gao, Guo, \& Zhao (2007) suggested that government guarantee has the characteristic of obstacle option, and they put forward the pricing model of "down-and-in put option" and "up-and-out put option" of government guarantee value, and then analyze the influence of two key factors, obstacle value and minimum guarantee income de- 
termined by guarantee level, on government guarantee value respectively. Zhang, Guo, \& Zhao (2009) and Wang, Guo, \& Sun (2009) have constructed the measurement model for government guarantee value of infrastructure project by discussing the option characteristics of floating return on investment government guarantee. They also establish the government guarantee pricing model based on jump-diffusion process by introducing Poisson distribution to depict the influence of unexpected events on government guarantee value, which is a further generalization on the original government guarantee pricing research. Wang, Guo, \& Sun (2008) have constructed the government guarantee value model based on the idea of contingent liabilities and real options, and also measure the effect of the change rate of the basic project, the expected rate of return and the degree of guarantee on the government guarantee value. Gong, Guo, \& Zhao (2009) established the value model of the multi-execution period of the minimum income government guarantee, and use the dynamic programming method to analyze the influence of the mean regression process on the government guarantee value. Wang, Guo, \& Gao (2008) also studied the hidden information problem of government guarantee in infrastructure project financing and the role of financial support of government guarantee in the PPP financing mode. As we can see, the previous studies above are almost rarely involved in the study of the selection on guarantee projects for government. For the government, there is always more than one project to choose. When the government faces a number of infrastructure projects to be guaranteed, how to choose the guarantee projects and choosing which projects to guarantee are realistic problems for the government.

Multi-objective programming is a branch of mathematical programming, which is gradually developed on the base of linear programming. At present, the multi-objective programming method has been widely used in the evaluation and decision-making of urban, economic and social development, and it has become a basic mathematical method to study the choice of multiple objects, the decision-making of investment schemes, the location of projects (Gong \& Wang, 2014) and regional development programming. So multi-objective programming is one of the effective tools to solve the multi-objective decision-making problems. Therefore, this paper intends to use the multi-objective programming method to help the government choose guarantee projects in infrastructure project financing, which is a multi-objective decision-making problem.

The paper is organized as follows. In Section 2, we briefly introduce the chance constrained programming method by reviewing the previous research. In Section 3, we put forward the main research problems to be solved. In Section 4, we build a chance constrained programming model. In Section 5, we conclude the main contributions of this study and look forward to future research.

\section{Chance Constrained Programming}

Multi-objective programming was first proposed by mathematicians (Charnes \& Cooper, 1961). A few years later, Ijiri (1965) introduced the concept of priority 
level and priority factor of goal in multi-objective programming and gave the improved multi-objective programming algorithm, which promoted the development of multi-objective programming. Lee (1972) published the first monograph on multi-objective programming, which summarized the concepts, algorithms and applications of multi-objective programming. After that, the multi-objective programming method has developed rapidly, constantly forming a variety of types of multi-objective programming and algorithms, and was gradually applied to various subject areas (Chen, 1986).

Multi-objective programming has the following characteristics. First, the method is flexible enough to deal with the situation of inconsistent units of measurement and mutual contradiction of multi-objects. Second, the use of "soft constraint" which can reflect whether the degree of resource value can be satisfied through positive and negative deviation variables. Third, the method has the expected target value as a clear goal, since the goal of decision-makers is to make the decision-making result as close as possible to the expected target value under the constraints of limited resources. In other words, the goal of decision-makers is to make the total deviation variable of the decision-making result and the expected target value smallest. Fourth, the method can provide a number of non-inferior solutions from which decision-makers can make appropriate choices under the actual situation (Xuan, 1993). Furthermore, multi-objective programming can also facilitate computerization and is therefore generally recognized by management decision makers.

In multi-objective programming, because of the existence of risk factors and various uncertainty factors, if the decision makers are not fully sure about the realization of a certain goal, but the goal is still regarded as a deterministic goal, then the goal will be difficult to achieve, that is, the goal programming will have no solution. However, if the decision maker releases the goal requirement to "the expected goal can be achieved with a certain probability", that is, the goal pursued by the decision maker is achieved with a certain feasibility, then the new goal constraint can be obtained by using the probability representation. This constraint, which represents the probability of expected goal realization, is called chance constraint. The objective programming with opportunity constraint is called multi-objective chance constrained programming (CCP) (Chen, 1987).

\section{Problem Statement}

Government guarantee for infrastructure projects means that government takes the risks that investors cannot control during the implementation of the project through consulting with investors. These risks include political risk, legal risk, regulatory risk, interest rate and exchange rate risk, etc., which are reflected in the relevant government guarantee clause of the franchise agreement. Political risk refers to the possible loss caused by government approval delays, suspension of concession contracts and non-payment of fees. Legal and regulation risk refers to the possible loss caused by the imperfect law in the process of signing, executing and supervising the project contract. Interest rate risk refers to the 
possible loss to the project when the uncertain market interest rate changes lead to the increase in the cost of raw materials and the depreciation of private capital. Exchange rate risk refers to the risk that the repayment cost of foreign exchange purchase will increase due to the devaluation of the currency in the country where the borrower is located. When the risks in the guarantee clause actually occur and affect the project income, the government will give certain investment compensation. So at the beginning of providing the guarantee, the government will not produce the cost immediately, but must bear the contingent liability, that is, the government has the potential guarantee payment obligation. At the same time, the financial budget is limited, excessive guarantee will increase the financial burden (Wang, Guo, \& Sun, 2009), so it is impossible for the government to guarantee all projects. The government will choose the appropriate BOT/PPP infrastructure project to guarantee.

The project guarantee clause of BOT/PPP project finance is set mainly from the negotiation results of private investors and government departments based on the project. And the fundamental purpose of the guarantee is to reduce the total cost of risk borne by the project participants. The guarantee provided by the government is mainly reflected in the commitment to the investment return of the project, the investment environment and conditions, and the franchise (Sun, Guo, Gao et al., 2007). This paper focuses on the government guarantee of the minimum income in the project.

The government's criteria for the selection of guarantee items are generally as following: 1) select the items that can obtain the maximum investment income; 2) select the items that can provide the minimum guarantee cost; 3) select the items that can produce the maximum change of income after the guarantee; 4) select the items with the least probability of excess payment (exceeding the annual financial budget). According to these criteria, the analysis indexes selected in this paper are as following: 1) the investment income of the project; 2) the guarantee amount of the project; 3 ) the change of the income after the project guarantee and the income before the guarantee; 4) the annual financial budget of the government. The investment income of the project is identified as net current value of the project. The guarantee amount of the project refers to the repayment guarantee made by the borrower or third party to the loan or leasing institution with its own credit or assets. The change of the income after the project guarantee and the income before the guarantee in this study is defined as the difference in investment income of the project before and after the adoption of the guarantee. The annual financial budget of the government refers to the government's annual financial revenue and expenditure plan approved by the legal procedure.

From the above analysis, we can see that the choice of BOT/PPP infrastructure guarantee project is essentially a multi-objective decision-making problem. The goal that the government should achieve when selecting the guarantee project is to select several optimal guarantee project combinations which can meet the above four selection criteria under the premise of ensuring the minimum in- 
come level of the project, which is also the problem to be solved in this paper. In the following analysis, we try to use the multi-objective chance constrained programming to construct a government model for the selection of guaranteed projects.

\section{Building a Chance Constrained Programming Model}

Because of the additive characteristic of net present value (NPV), the model selects net present value as the feasibility index of the project (Crundwell, 2008). NPV means that the sum of the net cash flow of each year discounts to the present value at the beginning of the project according to a certain discount rate during the life period of the project. It is a widely used evaluation index in the economic feasibility assessment of the current investment project and can reflect the profitability of the project investment. The NPV method is a way to evaluate the advantages and disadvantages of the scheme according to the size of the NPV. If the NPV is greater than zero, then the scheme is feasible. The larger the NPV is, the better the scheme and the investment benefit is. In this model, the economic feasibility of the project is measured by the economic net present value (ENPV); the financial feasibility of the project is measured by the financial net present value (FNPV). Therefore, this requires the government should analyze both the economic and financial ability of the project according to the method of this paper. Analysis of the economic ability is to assess the overall impact of a project on improving the economic welfare of citizens in the country (Economic and Development Resource Center, 1997) while the analysis of the financial ability of a project can assess whether the implementation of the project will bring commercial profits to investors (Perkins, 1994).

\subsection{Economic Constraints}

Economic net present value (ENPV) is selected as the feasibility index of the project under economic constraints. The NPV of the economy is the absolute index reflecting the net contribution of the construction project to the national economy. In any project investment decision analysis, the government only accepts economically viable projects. The primary objective of the government is to maximize the NPV of the total economy from guaranteed projects. In this paper, a variable with a wave line symbol $(\sim)$ indicates that the variable is random. For simplicity, assume that the project ENPV is clearly known or at least can be assumed. Note that the method of calculating ENPV here is not within the scope of this paper. The objective constraints under economic constraints are:

$$
\sum_{i=1}^{m} X_{i} E N P V_{i}-\delta_{E N P V}^{+}+\delta_{E N P V}^{-}=\sum_{i=1}^{m} E N P V_{i},
$$

where if the project $i$ is secured, then $X_{i}=1$, otherwise $X_{i}=0 ; m$ is the number of eligible projects (i.e. the number of projects to be selected), $E N P V_{i}$ is the economic net present value of project $i ; \delta_{E N P V}^{+}$is the positive deviation variable of 
the economic net present value target of the economy (exceeding the expected target); $\delta_{E N P V}^{-}$is the negative deviation variable of the economic net present value target (below the expected target). In the framework of goal programming, the deviation variable is an auxiliary variable, which is used to describe the difference between the decision value and the target value. The positive deviation variable represents the number of the decision value exceeding the target value, and the negative deviation variable represents the number of the decision value that does not reach the target value. Both are non-negative and their product is zero. The negative deviation variable below the expected goal will reduce the expected total economic net present value, so the negative deviation variable in Equation (1) should be minimized.

\subsection{Cost Constraints}

When all other conditions are the same, it is generally believed that governments prefer projects that generate less guarantee costs. We translate this traditional view into a minimized expected guarantee amount. Assume $C$ is the total amount of security payments expected at present value. The objective of minimizing expected total secured payments can be expressed as following:

$$
\sum_{\mathrm{i}=1}^{\mathrm{m}} X_{i} E\left(\tilde{G}_{i}\right)-\delta_{C}^{+}+\delta_{C}^{-}=C,
$$

in which $E\left(\tilde{G}_{i}\right)$ is the expected guarantee payment of the project $i$ at present value; $\delta_{C}^{+}$is the positive deviation variable of the total expected guarantee payment; $\delta_{C}^{-}$is the negative deviation variable of the total expected guarantee payment. The positive bias variable in Equation (2) should be minimized because it will increase the government's guarantee cost.

\subsection{Financial Impact Constraints}

Another important measure of whether a project can obtain government guarantees is its profitability. The goal we set is to maximize the total net change in the financial net present value before and after the project guarantee. We choose the financial net present value (FNPV) as the feasibility index of the project under the financial impact constraint. Financial net present value (FNPV) is the main dynamic evaluation index to investigate the profitability of the project during its calculation period. Although the previous goal was to minimize the expected total payment of the government-guaranteed project portfolio, the current goal is to maximize the expected benefits. This approach is similar to the traditional concept of cost-benefit ratio (BCR) assessment, which deals with them separately instead of aggregating the benefit and cost information into a single indicator. The goals of this paper are expressed in mathematical formulas as following:

$$
\sum_{i=1}^{m}\left[E\left(\overline{F N P V}_{i}^{*}\right)-E\left(\overline{F N P V}_{i}\right)\right] X_{i}-\delta_{B}^{+}+\delta_{B}^{-}=\sum_{i=1}^{m}\left[E\left(\overline{F N P V}_{i}^{*}\right)-E\left(\overline{F N P V_{i}}\right)\right],
$$


in which $E\left(\widehat{F N P V}_{i}^{*}\right)$ is the expected financial net present value of project $i$ after obtaining the guarantee; $E\left(\overline{F N P V}_{i}\right)$ is the expected financial net present value of project $i$ before obtaining the guarantee; $\delta_{B}^{+}$is positive deviation variable net change in financial net present value; $\delta_{B}^{-}$is negative deviation variable for total change in financial net present value. The negative deviation variable below the expected target should be minimized in Equation (3) because it will reduce the benefit of the project.

\subsection{Annual Financial Risk Constraints}

The guaranteed payment budget has always been an effective measure to control government fiscal expenditure. But the worst case that governments still need to consider is that guaranteed payments can theoretically go from zero to infinity. Therefore, the government must limit the possibility that the total annual guaranteed payment will exceed the annual budget allocation. This concept is called "excess payment probability" (Irwin, 2007). Under the framework of multi-objective chance constrained programming, the goal of reducing government financial risk can be modeled as following:

$$
P\left(\sum_{i=1}^{m} X_{i} \tilde{G}_{i t}>A_{t}\right) \leq \alpha, \quad t=1,2, \cdots, K
$$

in which $P$ is the probability; $\tilde{G}_{i t}$ is the guarantee for the project $i$ during the period $\mathrm{t} ; A_{t}$ is the annual financial risk budget allocated to the period $t ; a$ is the probability of allowing overpayment; and $K$ is the duration of the guarantee plan. Defining an annual financial risk budget is a portion of the funds that the government must allocate at a specific confidence level of $(1-\alpha)$, which represents the probability that the actual amount of guaranteed payment will not exceed the risk budget. If the $\alpha$ is set to 0.05 , then there are $95 \%$ confidence intervals where the actual payment is lower than the risk budget. Here it is worth noting that the risk budget or overpayment should not be confused with the expected payment, the former usually represents the worst payment situation, and the latter reflects the possible expected payment by the government.

The "safety first" principle (Roy, 1952) is adopted in the financial risk model, which means that investors are more willing to make investments which are less likely than "disaster levels" or target returns. Gaussian inequality states that if there is a random variable $\tilde{S}$ and mode $m_{s}$, mean $\mu_{s}$, and standard deviation $\sigma_{s}$, then for any positive value $k$, we have (Sellke, 1996):

$$
P\left(\left|\widetilde{S}-m_{s}\right|>k\right) \leq \alpha,
$$

where

$$
\alpha=\left\{\begin{array}{l}
\left(\frac{2 \tau}{3 k}\right)^{2}, k \geq \frac{2 \tau}{\sqrt{3}} \\
1-\frac{k}{\sqrt{3} \tau}, 0 \leq k \leq \frac{2 \tau}{\sqrt{3}}
\end{array},\right.
$$


and

$$
\tau^{2}=\left(\mu_{s}-m_{s}\right)^{2}+\sigma_{s}^{2}
$$

The inequality above is random distribution, as long as the information and mode of the first two moments are obtained. Mean and variance of the guaranteed portfolio for each period $t$ can be calculated as following:

$$
\begin{gathered}
E\left(\tilde{G}_{t}\right)=\sum_{i=1}^{m} X_{i} E\left(\tilde{G}_{i t}\right), t=1,2, \cdots, K \\
\sigma^{2}\left(\tilde{G}_{t}\right)=\sum_{i=1}^{m} X_{i}^{2} \sigma^{2}\left(\tilde{G}_{i t}\right)+2 \sum_{i=1}^{m} \sum_{\substack{j=1 \\
i \neq j}}^{m} X_{i t} X_{j t} \rho_{G_{i t}, G_{j t}} \sigma\left(\tilde{G}_{i t}\right) \sigma\left(\tilde{G}_{j t}\right), t=1,2, \cdots, K
\end{gathered}
$$

in which $E\left(\tilde{G}_{t}\right)$ is the expected guaranteed payment for the period $t ; E\left(\tilde{G}_{i t}\right)$ is the expected secured payment of the project $i$ for period $t ; \sigma\left(\tilde{G}_{t}\right)$ is the standard deviation of the expected guaranteed payment for the period $t$, and $\rho_{G_{i t}, G_{j t}}$ is the correlation coefficient between the government's guaranteed payments for project $i$ and $j$ for each period $t$.

Based on the single exponential model in financial theory (Edwin \& Martin, 2010), this study assumes that the linkage effect between two items is caused by a common factor directly correlating the operation of a single item with market changes, then the second term on the right of Equation (9) can be deleted; otherwise, the resulting correlation can be calculated again. This idea can simplify the calculation process.

Another question is how to obtain a clear representation for the mode. Here, the guarantee payment can assume mode as zero; if not, the government guarantee will no longer contain contingent liabilities, and will shift to a fixed liability, like a direct subsidy, which may occur when the threshold setting is far below (or above) the predicted value. For example, the government may be willing to guarantee 300 percent of the minimum predicted income in a project. But in fact, if the government is rational, there will be no such guarantee. In addition, the security payment distribution is truncated at zero. The validity of this hypothesis that the mode is zero can be easily verified by simulation. Substituting Equation (8) and Equation (9) into Equation (4)-(7), we can obtain:

$$
P\left(\sum_{i=1}^{m} X_{i} \tilde{G}_{i t}>A_{t}\right) \leq\left\{\begin{array}{l}
\frac{4}{9 A_{t}}\left\{\left[\sum_{i=1}^{m} X_{i} E\left(\tilde{G}_{i t}\right)\right]^{2}+\sum_{i=1}^{m} X_{i}^{2} \sigma^{2}\left(\tilde{G}_{i t}\right)\right\}, A_{t}>\lambda \\
1-\frac{A_{t}}{\sqrt{3\left\{\left[\sum_{i=1}^{m} X_{i} E\left(\tilde{G}_{i t}\right)\right]^{2}+\sum_{i=1}^{m} X_{i}^{2} \sigma^{2}\left(\tilde{G}_{i t}\right)\right\}}}, 0 \leq A_{t} \leq \lambda
\end{array}\right.
$$

in which

$$
\lambda=2 \sqrt{\frac{\left[\sum_{i=1}^{m} X_{i} E\left(\tilde{G}_{i t}\right)\right]^{2}+\sum_{i=1}^{m} X_{i}^{2} \sigma^{2}\left(\tilde{G}_{i t}\right)}{3}} .
$$

Under the principle of "safety first", we minimize the right part of inequality 
(10) rather than reduce the left of inequality (10). The following is the formula of multi-objective chance constrained programming model:

$$
\begin{gathered}
\frac{4}{9 A_{t}}\left\{\left[\sum_{i=1}^{m} X_{i} E\left(\tilde{G}_{i t}\right)\right]^{2}+\sum_{i=1}^{m} X_{i}^{2} \sigma^{2}\left(\tilde{G}_{i t}\right)\right\}-\delta_{G_{t}}^{+}+\delta_{G_{t}}^{-}=\alpha, A_{t}>\lambda \\
1-\frac{A_{t}}{\sqrt{3\left\{\left[\sum_{i=1}^{m} X_{i} E\left(\tilde{G}_{i t}\right)\right]^{2}+\sum_{i=1}^{m} X_{i}^{2} \sigma^{2}\left(\tilde{G}_{i t}\right)\right\}}}-\delta_{G_{t}}^{+}+\delta_{G_{t}}^{-}=\alpha, 0 \leq A_{t} \leq \lambda
\end{gathered}
$$

The goal under the financial risk constraint is to minimize the positive deviation variable because it increases the financial risk. One more complicated situation that may arise in reality is that the annual risk budget is random. In this case, the model can be constructed with unilateral Chebyshev inequality (Benzi et al., 2007), rather than Gaussian inequality.

\subsection{Objective Function and Model}

The ultimate goal of government is to reduce unnecessary deviation variables.

$$
\min Z\left(\delta_{E N P V}^{-}, \delta_{C}^{+}, \delta_{B}^{-}, \delta_{G_{1}}^{+}, \delta_{G_{2}}^{+}, \cdots, \delta_{G_{K}}^{+}\right),
$$

The multi-objective programming model can be divided into two subsets: weighted goal programming (WGP) and priority goal programming (PGP). In the WGP method, the decision maker can assign different weights to the deviation variables according to the relative importance of each goal, so that the weighted sum of the deviation variables can be minimized; in the PGP method, the decision maker sets the goal to many priority levels, and according to the priority order, the deviation variables that maintain the goal with higher priority reach the minimum in turn (Tamiz, Jones, \& Romero, 1998). Here WGP is chosen in this case, so formula (14) can be rewritten as following:

$$
\min Z=\omega_{E N P V} \delta_{E N P V}^{-}+\omega_{C} \delta_{C}^{+}+\omega_{B} \delta_{B}^{-}+\sum_{t=1}^{K} \omega_{G_{t}} \delta_{G_{t}}^{+},
$$

where $\omega_{E N P V}$ is the relative weight which is lower than the expected economic net present value target; $\omega_{C}$ is the relative weight which is higher than the expected total payment target; $\omega_{B}$ is the relative weight which is lower than the expected financial net present value change target; $\omega_{G_{t}}$ is the relative weight which is higher than the expected excess payment probability target for each period $t$.

Another problem in this multi-objective programming is that the units of measurement are not uniform, that is, the deviation variable is measured with different units but added directly, which may lead to the deviation of the results (Tamiz, Jones, \& Romero, 1998). This problem can be solved by normalizing the left-hand terms of all corresponding objective constraints. The left side of the Equation (12) and Equation (13) are divided by the corresponding goal value, and the optimization model can be rewritten as following: 


$$
\begin{gathered}
\min Z=\omega_{E N P V} d_{E N P V}^{-}+\omega_{C} d_{C}^{+}+\omega_{B} d_{B}^{-}+\sum_{t=1}^{K} \omega_{G_{t}} d_{G_{t}}^{+}, \\
F_{E N P V}-d_{E N P V}^{+}+d_{E N P V}^{-}=1, \\
F_{C}-d_{C}^{+}+d_{C}^{-}=1, \\
F_{B}-d_{B}^{+}+d_{B}^{-}=1, \\
F_{G_{t}}-d_{G_{t}}^{+}+d_{G_{t}}^{-}=1,
\end{gathered}
$$

when $A_{t}>\lambda$, we have $d_{E N P V}^{-}, d_{C}^{+}, d_{B}^{-}, d_{G_{1}}^{+}, d_{G_{2}}^{+}, \cdots, d_{G_{K}}^{+} \geq 0, X_{1}, X_{2}, \cdots, X_{m}=0$ or 1 . Here we have

$$
\begin{aligned}
& F_{E N P V}=\frac{\sum_{i=1}^{m} X_{i} E N P V_{i}}{\sum_{i=1}^{m} E N P V_{i}}, \\
& F_{C}=\frac{\sum_{i=1}^{m} X_{i} E\left(\tilde{G}_{i}\right)}{C}, \\
& F_{B}=\frac{\sum_{i=1}^{m}\left[E\left(\overline{F N P V}_{i}^{*}\right)-E\left(\overline{F N P V}_{i}\right)\right] X_{i}}{\sum_{i=1}^{m}\left[E\left(\overline{F N P V}_{i}^{*}\right)-E\left(\widehat{F N P V}_{i}\right)\right]}, \\
& F_{G_{t}}=\left\{\begin{array}{l}
\frac{4}{9 A_{t} \alpha}\left\{\left[\sum_{i=1}^{m} X_{i} E\left(\tilde{G}_{i t}\right)\right]^{2}+\sum_{i=1}^{m} X_{i}^{2} \sigma^{2}\left(\tilde{G}_{i t}\right)\right\}, A_{t}>\lambda \\
\frac{1}{\alpha}-\frac{A_{t}}{\alpha \sqrt{3\left\{\left[\sum_{i=1}^{m} X_{i} E\left(\tilde{G}_{i t}\right)\right]^{2}+\sum_{i=1}^{m} X_{i}^{2} \sigma^{2}\left(\tilde{G}_{i t}\right)\right\}}}, 0 \leq A_{t} \leq \lambda
\end{array}, t=1,2, \cdots, K,\right.
\end{aligned}
$$

The multi-objective chance constrained programming model can help the government choose the appropriate guarantee projects which can obtain the maximum investment income, provide the minimum guarantee cost, produce the maximum amount of income change before and after the guarantee and make the annual financial risk budget least.

\section{Conclusion and Future Research}

Government guarantee is one of the main means for projects to share risk and plays a vital role in BOT/PPP project financing. Based on reviewing and summarizing the previous research on government guarantee factors, guarantee concession period and guarantee value, this paper puts forward the importance of research on the government choice of guarantee project. Based on the theory of multi-objective programming, this paper analyzes the criteria of government guarantee project selection. We find out that the choice of government for BOT/PPP infrastructure guarantee project is essentially a multi-objective decision-making problem. Therefore, we try to establish a multi-objective chance 
constrained programming to solve this problem, and provide method for the government to make the decision on the choice of guarantee project.

This study has two main contributions to the previous research.

- The present study contributes to the project finance literature based on government guarantees by involving in the issue of selection of government guarantee projects. For governments, they often guarantee more than one project, and it is an outstanding question as to how to choose the guarantee project and which projects to guarantee when the government faces several infrastructure projects to be secured.

- This paper also contributes to the project selection research by addressing the situations in which decision makers are not sufficiently sure of the achievement of a given objective due to risk factors and uncertainties. By adopting chance constrained programming, we set the decision maker's target constraint to the expectation expressed by a probability.

This study has the following practical significance for the development of government guarantee in BOT/PPP project financing:

- Make the guarantee project clear and avoid the blind guarantee and excessive guarantee. Because of the different attributes of infrastructure project construction and the limitation of government budget, it is impossible for the government to guarantee all BOT/PPP infrastructure projects. The multi-objective chance constrained programming model proposed in this paper can clearly screen out the projects that meet the selection criteria and can achieve the expected goals of the government. In this way, the government can avoid the waste of financial funds and the increase of financial burden caused by the blind guarantee and excessive guarantee.

- Select the optimal guarantee projects and maximize the economic and social value of government financial funds. Considering that government generally provides guarantees for multiple projects at the same time, we define the objective function constructed in this paper to minimize the weighted sum of unnecessary bias variables. Through this way, the government can get a set of combinations of guarantee projects which are optimal relative to the expected goal and meanwhile produce the maximum economic and social benefits.

The limitation of this study is that we do not consider the annual financial risk budget of idle funds. The idle funds may represent the loss of time value, and some idle financial funds can be used to generate income to reduce the financial burden. For the future research, we plan using Monte Carlo simulation and crystal ball risk management software to solve this model so that improving its practical value. By using crystal ball risk management software to iterate through Monte Carlo simulation, future study will obtain the data of investment income e and guarantee payment needed in models. The simulation is helpful for the researchers to analyze and verify the validity of the model and to illustrate the advantages of the opportunity-constrained target planning method. 


\section{Conflicts of Interest}

The author declares no conflicts of interest regarding the publication of this paper.

\section{References}

Benzi, M., Benzi, M., \& Seneta, E. (2007). Fransesco Paolo Cantelli. International Statistical Review, 75, 127-130. https://doi.org/10.1111/j.1751-5823.2007.00009.x

Charnes, A., \& Cooper, W. W. (1961). Management Models and the Industrial Applications of Linear Programming. Journal of the Franklin Institute, 272, 334. https://doi.org/10.1016/0016-0032(61)90580-4

Chen, Y. (1986). Multi-Objective Hierarchical Planning and Its Application. Systems Engineering, 4, 12-17. http://www.cnki.com.cn/Article/CJFD1986-GCXT198604001.htm

Chen, Y. (1987). Goal Planning with Opportunity Constraint and Its Application in Risk Investment Decision Making. Systems Engineering, 5, 24-31. http://www.cnki.com.cn/Article/CJFDTotal-GCXT198704004.htm

Crundwell, F. K. (2008). Finance for Engineers: Evaluation and Funding for Capital Projects. London: Springer-Verlag KG.

Dai, D. (2012). Financing of Projects. Beijing: Machinery Industry Press.

Economic and Development Resource Center (1997). Guidelines for the Economic Analysis of Projects. Manila: Asian Development Bank.

Edwin, J. E., \& Martin, J. G. (2010). Modern Portfolio Theory and Investment Analysis. Toronto: Wiley.

Gao, F., Guo, J., \& Zhao, Q. (2007). The Barrier Options-Based Research of the Value of Government Guarantees in Infrastructure Projects. Forecasting, 26, 76-80.

Gao, L., Zhang, C., Du, Y., \& Ni, K. (2005). Research on Guarantee Value of Government Economic Policy in BOT Project Financing Based on Real Option Theory. Market Modernization, 11, 344-345.

Gong, L., Guo, J., \& Gao, F. (2011). Empirical Research on the Government-Guaranteed Infrastructure Factors and Effect on the Investment Incentives. Operations Research and Management Science, 20, 164-172.

Gong, L., Guo, J., \& Zhang, G. (2008). Negotiating Game Model for Concession Period of Infrastructure BOT Project. Statistics and Decision, No. 4, 153-155.

Gong, L., Guo, J., \& Zhao, Q. (2009). Infrastructure Project Government Guarantee Value Research Based on Ornstein-Uhlenbeck Process. Science and Technology Progress and Policy, No. 7, 36-40.

Gong, M., \& Wang, L. (2014). Study of Mines Transformation Projects Optimization Based on the 0-1 Goal Programming Optimization. Science and Technology Management Research, No. 13, 174-177.

Huang, X., \& Liu, S. (2008). Study on the Implementation Mechanism of Risk Sharing for Project Financing. Modern Business, No. 17, 220.

Ijiri, Y. (1965). Management Goals and Accounting for Control. Operational Research Society, 17, 486. https://doi.org/10.2307/3007458

Irwin, T. (2007). Government Guarantees: Allocating and Valuing Risk in Privately Financed Infrastructure Projects. Washington DC: World Bank. https://doi.org/10.1596/978-0-8213-6858-9

Lee, S. M. (1972). Goal Programming for Decision Analysis. Philadelphia: Auerbach Pub- 
lishers.

Lin, M., Chen, J., \& Ma, S. (2005). An Optimized Capital Structure Model in Construction Project Financing. Optimization of Capital Construction, 26, 53-56. http://www.cnki.com.cn/Article/CJFDTotal-JJYH200505017.htm

Perkins, F. (1994). Practical Cost Benefit Analysis: Basic Concepts and Applications. South Melbourne: Macmillan Education Australia.

Roy, A. D. (1952). Safety First and The Holding of Assets. Econometrica, 20, 431-449. https://doi.org/10.2307/1907413

Sellke, T. (1996). Generalized Gauss-Chebyshev Inequalities for Unirnodai Distributions. Metrika, 43, 107-121. https://doi.org/10.1007/BF02613901

Sun, Y., Guo, J., Gao, F., \& Zhang, G. (2007). Government Guarantees in Infrastructure Project Financing. Statistics and Decision, 20, 53-56.

Tamiz, M., Jones, D., \& Romero, C. (1998). Goal Programming for Decision Making: An Overview of the Current State-of-the-Art. European Journal of Operational Research, 111, 569-581. https://doi.org/10.1016/S0377-2217(97)00317-2

Wang, L., Guo, J., \& Gao, F. (2008). Financial Support in Infrastructure PPP Model with Government Guarantees. Scientific Management Research, No. 3, 104-106.

Wang, L., Guo, J., \& Sun, Y. (2008). Valuation of Government Guarantee in Infrastructure Financing with Real Option Method. Operations Research and Management Science, 17, 112-117.

Wang, L., Guo, J., \& Sun, Y. (2009). Comparative Research on Float Return Government Guarantee in Infrastructure Finance. Operations Research and Management Science, $18,124-127$.

Xuan, J. (1993). Characteristics and Progress of Objective Planning. Journal of Operational Research, 12, 34-43. http://www.cnki.com.cn/Article/CJFD1993-YCXX199301004.htm

Ye, X., \& Zhou, C. (2010). The Studying of Building Model for Dynamic and Integrated Risk Management of PPP Projects. Science and Technology Management Research, 30, 129-132.

$\mathrm{Yu}, \mathrm{X}$. , Zhou, J., \& Wu, X. (2012). Game Analysis of the Financing of Large Cross-Border Project. Soft Science, No. 1, 30-35.

Zhang, G., \& Guo, J. (2009). Research on Infrastructure Financing Projects' Incentive and Monitor Problems. Soft Science, No. 3, 76-79,93.

Zhang, G., Guo, J., \& Zhao, Q. (2009). Infrastructure Financing Project Government Guarantee Value Research Based on Jump-Diffusion Process. Forecasting, 28, 60-64.

Zhao, H., \& Wang, X. (2010). Study on the Selection of Financing Model for Infrastructure Projects Based on RS and GCA. Statistics \& Decision, No. 10, 169-171. http://www.cnki.com.cn/Article/CJFDTotal-TJJC201010058.htm 